\title{
Necessity and Effective Ways of Humanistic Quality Education for Engineering Students in Higher Vocational Colleges
}

Wei Wei

Shandong Transport Vocational College,Weifang, Shandong, PR China (wfx2003sds@163.com)

Abstract - Humanistic quality education is the foundation of University education. Strengthening humanistic quality education has become an important content of higher education reform in china. Engineering students' comprehensive quality promotion also determines the level of science and technology development of China, All this requires Vocational College of engineering students have a good professional knowledge and accomplishment. Besides, pay more attention to cultivate their humanistic quality to meet the needs of social development.

Keywords - Higher vocational colleges, Science and Engineering, Humanistic Quality Education, Effective ways

\section{探析加强高职院校理工科学生人文素质教育的必要性 和有效途径}

\author{
魏伟 \\ 山东交通职业学院, 潍坊, 山东, 中国
}

摘 要 人文素质教育是大学教育之根本, 加强人文素质教育已经成为我国高等教育改革的一项十分重要的内容。理工科学生综 合素质的提升也在很大程度上决定了我国科学技术发展水平的高低, 这一切都要求高职院校理工科学生除了具备良好的专业知识与素 养外, 更应该重视培养自身的人文素质, 以适应社会发展的需要。本文试图从分析我国高职院校理工科学生的人文素质现状入手, 阐 述加强高职院校理工科学生人文素质教育的必要性和有效途径。

关键词＼cjkstart高职院校，理工科，人文素质教育，有效途径

\section{1. 引言}

当前, 高等职业教育的重要目标是培养“下得去、用得 上、留得住、上手快”的生产、经营、服务第一线高级应用 性专门人才。对我国而言, 高职院校理工科学生综合素质 的提升也在很大程度上决定了科学技术发展水平的高低。 因此, 这要求高职院校理工科学生除了具备良好的专业知 识与素养外, 更应该重视培养自身的人文素质, 以适应社 会发展的需要。但实际上, 许多高职理工科院校只把培养 学生的技术作为终极目标, 而忽视了对学生的人文素质教 育。再加之受其他诸多因素的影响, 势必会影响到学生的 全面发展。如何使学校和学生对人文素质教育有一个清晰 的认识, 如何积极探索并采取有效措施改进人文素质教育,
已成为高职理工科院校所面临的刻不容缓的任务。

2. 高职院校理工科学生人文素质现状不容乐观

近些年,在对理工科学生实施素质教育的过程中, 高职 院校注意加强了对学生人文素质的教育和培养, 在进行人 文素质教育的过程当中, 也确实取得了一些成绩。但从现 状看, 在高职理工科专业中, 仍不同程度地存在着重技能、 轻人文, 重专业、轻基础, 重智育、轻德育的倾向, 学生 人文素质的教育和培养在一定程度上受到了忽略。不少理 工科学生基本的应用文不会写, 写文章时错别字连篇。他 们专业技能不错, 但人文精神缺失, 他们关注物质, 急功 近利。他们进入社会以后, 由于人文修养的缺乏, 存在很 
多诸如无法正确处理和同事之间的人际关系、无法及时适 应进入社会以后角色转变等的问题, 也因此直接导致其社 会适应能力较为低下。另外, 当今的物质社会也让学生在 学校所接受的专业教育在不知不觉中带有了复杂的功利色 彩, 实用主义和物质化的心态在高职院校理工科学生心中 不断蔓延, 导致学生在进入社会以后容易表现出注重眼前 既得利益而缺乏内心人文关怀的心态, 对他人、对单位、 对社会缺乏奉献精神, 在某种程度上容易丧失个人对自我 和社会责任感。这与高等教育应当培养出德智体美全面发 展的高素质人才的要求是不相符的。

\section{3. 影响高职院校理工科学生人文素质的原因分析}

3.1 社会大环境导致高职理工科学生缺乏人文素质培养意 识

中国是一个有着优秀传统的国度, 但是改革开放以来, 市场经济的逐渐深入, 人们关注更多的是经济生活和物质 享受，出现类似的很多“拜金主义”。高等职业院校的教育 是由学生到社会人的一个过度的环境, 学生思想没有成熟, 是非的辨别能力还不够明确, 高等职业院校的学生又是一 个很敏感的群体, 社会发展进程中的风吹草动都会对他们 的思想和意识有一定的影响。

\section{2 知识结构不合理导致高职理工科学生文化素养薄弱}

受实用主义思潮的影响, 高职院校专业设置往往过紧、 过专, 学生缺乏对除自己专业之外的其他专业的了解, 这 就导致高职理工科学生普遍人文知识面偏窄, 知识结构单 一。尽管部分高职院校也开设了各类人文学科选修课程, 但相对于重头的专业课来说, 少量的课时及落后的教学设 备却无法满足学生对人文知识的需要。这样往往导致一些 学生人文知识缺乏, 审美情趣偏低, 对一些基本的历史文 化知识缺乏了解, 对现实世界、现实社会的认识肤浅, 还 有一些学生语言文字功底较为薄弱, 甚至缺乏基本的对语 言文字的理解与表达能力。

\section{3 学生个人素质导致高职理工科学生缺乏正确的自我认} 识

在高考招生的过程中, 高等职业教育被放在最后一批 录取, 又由于高等教育的大面积扩招, 最终被录取的高等 职业院校的学生的普遍分数较低, 甚至有些学院的分数不 到 300 分, 虽然分数不是学生人文素质的直接体现, 但是 分数的高低多少反映高等职业院校学生的一些问题, 如学 习态度不积极, 自身的责任感差, 沉溺网络, 对学习没有 兴趣。高职学生进入学校后普遍缺乏普通本科学生的自信
心和自豪感, 特别是一些刚刚升格进入高职高专层次学校, 由于各种原因, 常常让学生感到缺乏大学氛围。在这样的 环境中, 学生大都觉得没有“上大学”的感觉, 而有这种情 绪状态导致的悲观、失望、冷漠等情绪波动, 更易导致学 生心理失衡, 从而无法正确认识自我, 产生深深的自卑感。 在这样的情况下, 高职理工科学生的人文素质普遍较低的 现象就可想而知了。

\section{4. 加强高职理工科学生人文素质教育的有效途径}

4.1 抓好课堂主渠道, 构建针对理工科学生的人文教育课 程体系

构建针对理工科学生合理的人文素质教育的课程体 系, 是加强人文素质教育最基本的途径。现阶段高职理工 科学生的人文素质课程主要包括“思想政治教育课”和学校 的各类选修课。除了重视“思想政治理论课”教学, 积极探 索提高教学质量以外, 选修课的开设就成了提高学生人文 素质的重要途径, 因此, 必须构建选修课科学的教学内容 和课程体系。要在高职理工科专业的教学计划中开设几门 覆盖面广、有代表性, 能包含文科教育核心内容的必修课 程，如大学语文、政治经济学、文化科技史等; 另外，还应 开设面向全校的人文素质类公共选修课, 起到必修课的补 充和延伸的作用，在其内容上，应强调文、史、哲、艺术 等多学科门类知识的融合, 如开设逻辑学、伦理学、心理 学、法学、历史学、公共关系学、应用写作、艺术欣赏等 类课程, 规定学生按各自不同专业完成相应的人文素质教 育学分, 不断丰富学生的人文知识, 提高学生的自身修养, 提升学生的人文境界。

4.2 在各学科教学过程中渗透人文教育, 注重专业渗透和 实践体验

在专业理论课与专业技能课教学中, 高职理工科专业 可尝试将人文教育内容纳入专业培养目标, 落实到教学计 划和课程设置之中。因为从现实来看, 无论我们怎样看重 人文教育的作用, 高职院校学生最关心、花时间和精力最 多的还是专业教育课程, 所以如何使人文教育突破学科的 界限, 以渗透的方式融进专业教育之中, 这也是加强人文 教育的关键。可尝试开设从专业课或专业基础课中分化或 延伸出来的专业文化课, 引导专业课教师在专业教育中主 动承载起人文教育的责任。通过在专业教育中渗透人文教 育, 可以让学生正确认识技术与社会的关系, 技术与人的 关系，克服技术至上的观点，懂得技术是为人服务的，在 技术服务中也要体现对人的关怀。同时，任何一门自然科 学、专业技术科学都有自己发展的历史, 在其发展历史中 
渗透着哲学的思想, 体现着杰出的科学家和科学工作者敬 业奉献的精神。挖掘这些学科古今中外科学家的成就、治 学的精神、成才的道路、研究的方法和哲学思想, 以他们 为楷模, 教育青年一代, 也是最好的人文精神教育。

4.3 加强教师队伍建设, 发挥教师在人文素质教育中的主 导作用

教师的一言一行, 对学生都可能产生重要的影响。因 此, 教师首先要深入认识到人文教育的重要性, 坚持以人 为本的理念, 树立人才培养中的科学发展观, 为每一位学 生的成长, 成材负责。职业学院在引进新教师的时候, 不 仅要重视应聘人员的专业方面的考核, 更重视其人文素质, 如写作能力, 交际能力, 各方面的人文综合能力。鼓励在 职教师积极进行教学研究, 发挥教研室的作用, 教研室会 议不仅探讨专业方面的知识, 更要探讨强化人文教育的好 方法, 取得经验并加以推广。学院要不断组织教师、班主 任、辅导员参加培训, 学习和交流经验, 提高自身人文素 质和管理水平, 建设一支思想素质好、业务水平高、勤奋 敬业、责任心强、热爱学生、有奉献精神的高素质教师、 管理队伍, 以其自身的人文素养熏染学生, 提高他们的人 文素质。

4.4 营造健康高雅的校园文化氛围, 拓宽人文素质培养途 径

一方面, 通过开展丰富多彩的活动, 加强人文素质的 培养, 有计划地聘请著名科学家、艺术家、社会学家等担 任学校的兼职教授, 为学生进行人文社会科学系列讲座与 自然科学讲座; 充分利用学生资源, 广泛开展各种主题活 动, 发挥学生组织在人文素质培养中的作用, 通过各种宣 传形式, 弘扬良好的人文精神, 优化育人环境; 加强校园
文化和校风教风学风建设, 定期对学生进行心理健康教育。 另一方面, 有计划、有重点地加强校园人文景观的建设, 如历代文化名人的塑像、各种体现人文主题的雕塑建筑等, 既可以美化校园环境, 又可以对学生进行历史文化教育和 审美情操的陶冶, 间接地提高了学生的人文素质。

\section{5 加强社会实践环节, 拓展人文素质培养空间}

多彩的现实生活, 也是进行人文教育的最好课堂, 因 为在不断涌现出的时代英雄和先进人物身上, 都体现着深 刻而富有时代特征的人文精神。因此, 学校要有计划、有 目的地组织学生深入社会, 深入生活, 亲身感知和体验人 文精神。从某种意义上说, 来自社会实践的人文教育, 其 深刻性、丰富性和持久性是校园所无法比拟的。

\section{5. 结语}

综上所述, 加强高职院校理工科学生的人文素质教育, 对社会、对学校、对学生自己都是十分必要的, 在高等职 业教育中应该重视理工科学生人文知识与人文精神的培 养, 努力提高其人文素质, 为社会主义现代化建设培养出 更为优秀的建设者和接班人。

\section{参考文献(References)}

[1] Chen Hong, "How to strengthen the humanistic quality education in Higher Vocational Colleges", Quality Education Forum, the second half of the month, 2007.06.

[2] Wang Xinju, Investigation and Thinking on humanities quality of engineering studentsin Higher Vocational Colleges, Today Keyuan,2010.14.

[3] Hu Xuefeng, "Science students' Humanistic Quality Cultivation in College of Engineering", The study of Higher Education (Chengdu), 2007.01. 